\title{
Financial Geographical Structure and the Gap of Green Development: Evidence from Chinese Cities
}

\begin{abstract}
Jianhua Zhao
Economics and Management School, Wuhan University, Wuhan 430072, China

Correspondence should be addressed to Jianhua Zhao; 2017101050040@whu.edu.cn

Received 23 January 2022; Revised 10 February 2022; Accepted 15 February 2022; Published 2 March 2022

Academic Editor: Miaochao Chen

Copyright (c) 2022 Jianhua Zhao. This is an open access article distributed under the Creative Commons Attribution License, which permits unrestricted use, distribution, and reproduction in any medium, provided the original work is properly cited.

In the context of common prosperity, it is of great significance to explore the influence and mechanism of financial development on the gap of green development. This study takes 250 prefecture-level cities in China from 2003 to 2019 as the research object and empirically tests the influence of financial development on the gap of green development by using the super-efficiency SBM model, the two-way fixed effect model, and the mediating effect model. It is found that local financial effect can significantly narrow the gap of green development, while financial spillover effect of the central city can widen the gap of green development. The mechanism analysis shows that enhancing the advancement of human capital helps to optimize the utilization efficiency of financial resources outside the city and thus narrows the gap of green development. Local financial effect narrows the gap by the optimization of industrial structure, the improvement technological innovation, and the decrease of resource dependence, while financial spillover effect narrows the gap only by the optimization of industrial structure. The heterogeneity analysis demonstrates that local financial effect significantly narrows the gap of green development in cities that are 100-200 KM away from the central city in the central region, while financial spillover effect significantly enlarges the gap of green development in cities that are 100-300 KM away from the central city in the western region. The research in this paper facilitates the understanding of the influence of financial development on the gap of green development and puts forward relevant policy suggestions.
\end{abstract}

\section{Introduction and Literature Review}

With more than 40 years of reform and opening up, China's economy has progressed rapidly and become the second largest economy in the world. The economic growth rate has gradually changed from high growth in the past to stable development, and China's economy has entered the "new normal" of economic development. In the "new normal" stage, the goal of economic development has modified from the pursuit of total economic growth in the past to quality growth. The Fifth Plenary Session of the 19th CPC Central Committee puts forward that green development should be regarded as an essential goal of the 14th Five-Year Plan and pointed out that China should pay close attention to the transformation of industrial structure and the high-quality economic development. High-quality development is essentially a value-oriented concept of "quality" and "efficiency," which is an integration of innovative, coordinated, green, open, and shared development. Due to China's vast territory, the quantity and quality of resource elements vary largely between regions. Coupled with the administrative intervention of the government, some areas have a high level of green development, while some areas are still in extensive and energy-intensive economic development, and the level of green development is unbalanced among different regions. The concept of collaborative development put forward by President Xi Jinping provides ideas for carrying out green development of economy and society in the new period. The green development inherently requires that green ideas permeate all aspects of the economy and society, including production, life, politics, and culture. The collaborative development is to reintegrate resources, enhance the overall green development level of all areas, and ultimately promote the coordinated development of all regions, thereby narrowing the current gap of regional green development in China. 
Ouyang Weimin, president of the China Development Bank, pointed out that the capital needed for green development is enormous. If we want to achieve the goal of peak carbon dioxide emissions and carbon neutrality, it will cost at least one trillion yuan. It is far from enough to rely solely on the government for green development, and it also requires the financial system to play its role. The distribution of China's financial resources is unbalanced due to the natural environment and various factors in different places. In recent years, the national financial resources are gradually gathering in the central city. The "China Financial Center Index" shows that the added value of financial industry in 31 central cities, namely, municipalities directly under the Central Government and provincial capitals, accounts for $54 \%$ of the added value of national financial industry, and their financial assets account for $81 \%$ of the total assets of national commercial banks. However, although the economic development level of small- and medium-sized cities and remote areas is accelerating, the supply of financial resources is not sufficient. Hence, the supply of financial elements in small- and medium-sized cities is particularly crucial for green development.

The study of financial geographical structure dates back to the 1970s, when Conzen [1] puts forward financial geography. Later, some scholars began to explore the spatial characteristics of financial elements and gradually found that financial centers presented remarkable features of spatial hierarchical distribution and increasingly concentrated towards regional centers with the advancement of information technology [2]. Existing research studies mainly focus on the causes of financial cluster and the effect of financial cluster, as well as the spatial distribution of financial elements. The causes of financial cluster primarily focus on economies of scale, information asymmetry, and center-periphery theory. Financial cluster can effectively promote the upgrading of industrial structure and thus boost economic growth [3-8]. Since the ultimate orientation of financial cluster is to form a financial center, the location of the financial center will affect the development of the real economy. The external financing threshold of enterprises close to the financial center drops, making them easier to obtain funds, while enterprises far away from the financial center confront the rising difficulty in financing [9-12]. This fully demonstrates that the financial geographical structure can affect the operation of the real economy. Under the goal of common prosperity, financial elements should not be ignored when exploring the approach to narrow the gap of green development.

The change of China's financial geographical structure is closely associated with the economic system. All of the current financial centers in China are established with the involvement of the government [13]. Since green development requires the participation of financial elements, can the financial center built in China help to reduce the gap of regional green development? In other words, can the spillover effect of the financial center in provincial capitals narrow the gap of green development in the province? In addition, when China's financial resources flow in various regions, there are often various institutional barriers, which leads to the spillover effect of the financial center being affected by the distance. Subsequently, the radiation degree of its spillover effect is affected, thus accelerating the speed of local financial development to some extent. However, due to the local infrastructure and other factors, local finance has not received much attention from relevant departments, and there is a lack of sound supporting policies and regulatory mechanisms [14]. Hence, compared with the financial center, is local finance more beneficial to local green development and thus narrows the gap of green development in different places? Based on this, this study focuses on financial geographical structure and the gap of green development, and it further explores whether financial geographical structure can narrow the gap of green development.

The possible marginal contributions of this paper are as follows. On the one hand, from the perspective of geographical structure, this study discusses the influence of financial development in the central city and local cities on the gap of green development. It enriches the literature on the relationship between financial geographical structure and the gap of green development. On the other hand, this study finds that the advancement of human capital is its optimization mechanism, while the optimization of industrial institutions, the improvement technological innovation, and the decrease of resource dependence are its transmission mechanisms.

\section{Research Design}

2.1. Econometric Model. According to the previous theoretical analysis, this paper examines the mechanism of the influence of the financial geographical structure on the gap of regional green development from the finance of central city and local finance. The model is set as follows:

$$
\begin{aligned}
\operatorname{Gtfp} \_g a p_{i t}= & \alpha_{0}+\alpha_{1} \text { Fin_local }_{i t}+\alpha_{2} \text { Fin_center }_{j t} \\
& +\alpha_{3} \text { Controls }_{i t}+\delta_{i}+\varphi_{t}+\varepsilon_{0},
\end{aligned}
$$

where the subscript $t$ indicates the corresponding year, $i$ and $j$, respectively, indicate the local cities and the central city (provincial capital) of each province, Gtfp_gap ${ }_{i t}$, Fin_local ${ }_{i t}$, and Fin_center ${ }_{j t}$, respectively, represent the gap of urban green development, the local effect of local financial development, and the spillover effect of regional financial center, Controls $s_{i t}$ is the control variable set according to existing literature, $\delta_{i}$ represents the fixed effect of the city, $\phi_{t}$ indicates the fixed effect of time, and $\varepsilon_{0}$ is the random disturbance term.

2.2. Variable Measurement. Measurement of the urban green development level: the existing literature mainly measures green development by constructing the evaluation system and measuring the green total factor productivity. Based on the method of Pastor et al., this study measures urban total factor productivity growth by integrating the super-efficient SBM model considering nonexpected output and Malmquist productivity index under the framework of global reference set in data envelopment analysis [15]. The 
description of the selected indicators in this study is shown in Table 1, in which the input-output data mainly come from China City Statistical Yearbook and statistical bulletins of various provinces over the years. Meanwhile, the depreciation rate of physical capital stock is set at 9.6\%. The PM2.5 concentration is derived from satellite remote-sensing data published by NASA and China's basic geographic information.

Measurement of the gap of green development: the central city has a higher city level, and it has comparative advantages in material capital and human capital. The green development of the central city is generally at a higher level. Therefore, this study sets the central city as the reference city and defines the gap of green development as the difference between the green development level of the central city and that of other cities in the province. The formula is as follows:

$$
\text { Gtfp_gap }_{i t}=\mathrm{Gtfp}_{j t}-\mathrm{Gtfp}_{i t},
$$

where $i$ and $j$, respectively, represent local cities and the corresponding central city in each province, $t$ represents the corresponding year, Gtfp_gap ${ }_{i t}$ represents the gap of green development in local cities, Gtfp $\mathrm{j}_{\mathrm{jt}}$ represents the green development level of the central city in the province, and Gtfp represents the green development level of local cities in the province.

This study employs financial scale to measure the level of financial development. China has a financial system with banking as the main body, so the development level of financial institutions can indicate the level of financial development. By referring to the research of $\mathrm{Xia} \mathrm{Cao}$ and Lupeng Zhang, the ratio of the loan balance of financial institutions to GDP in various regions is used to represent the financial scale [16]. The specific calculation formula is as follows:

$$
\text { Fin_local }{ }_{i t}=\frac{\operatorname{Fin}_{i t}}{\mathrm{GDP}_{i t}} \text {, }
$$

where $i$ represents the local cities in each province, $t$ represents the corresponding year, Fin $_{i t}$ indicates the financial development scale of local cities $i$ in $t$, and $\mathrm{GDP}_{i t}$ represents the GDP of local cities $i$ in $t$.

Measurement of financial spillover effect: China's financial system has special administrative geographical boundaries, and its financial activities are often confined by provincial boundaries. Therefore, this study takes provincial boundaries as the distance boundary of financial spillover effect. Referring to the research of Klagge and Feng Tao, the distance between the central city and local cities is included in formula (3) to describe the distance attenuation characteristics of spillover effect [9]. The specific formula is as follows:

$$
\text { Fin_center }_{i t}=\frac{\operatorname{Fin}_{i t}}{\left(\operatorname{GDP}_{j t} * \operatorname{Dis}_{i j}\right)},
$$

where $i$ and $j$, respectively, represent local cities and the corresponding central city in each province, $t$ represents the corresponding year. Fin $_{i t}$ represents the financial development scale of the central city $j$ in each province in $t$, $\mathrm{GDP}_{\mathrm{jt}}$ represents the GDP of the central city $j$ in each province in $t$, and $\mathrm{Dis}_{\mathrm{ij}}$ represents the spherical distance between local cities $i$ and the central city $J$ in each province. This study uses latitude and longitude to calculate the distance between the central city and local cities in the province to describe the information cost and service cost of financial institutions.

First, the relationship between the financial development level of local cities and the gap of green development is simply evaluated. For the convenience of observation, the reciprocal of the financial development level of local cities is recorded as finra. The median of finra and gtfp_gap is used as a node draws the graph. Figure 1 shows that the gap of green development (gtfp_gap) is more significant when finra is larger, namely, the financial development level of local cities is lower. Moreover, the gap of green development fluctuates slightly around 0 when finra is larger, namely, the financial development level of local cities is higher. It preliminarily shows that the improvement of the financial development level of local cities helps to narrow the gap of green development, but other factors need to be controlled to obtain more rigorous evidence.

Based on the existing literature, this study controls the following variables. The economic development level (lnpgdp) is represented by the natural logarithm of per capita GDP. The city size (lnpopulation) adopts the natural logarithm of city population density. The foreign investment (fdi) is measured by the ratio of foreign investment converted by the exchange rate to regional GDP. The fiscal decentralization (Finadp) is measured by the ratio of local budget revenue to local budget expenditure. The medical level (medical) is measured by the number of practicing (assistant) doctors per 10,000 people. All the data in this paper are from China City Statistical Yearbook and China Statistical Yearbook, and all the price-related indicators are deflated based on 2003. Finally, the balanced panel data of 4,250 observations in 250 prefecture-level cities in China from 2003 to 2019 are constructed, and the results of descriptive statistics are shown in Table 2.

\section{Empirical Results and Economic Explanation}

3.1. Baseline Regression. Before exploring the relationship between financial geographical structure and the gap of green development, we should first test whether the financial level can promote green development. Columns (1) and (2) of Table 3 shows the effect of financial level on green development. The estimated coefficient of local financial effect (fin_local) on green total factor production is positive and significant at the level of $5 \%$. Therefore, it can be considered that the advancement of the financial level contributes to the improvement of the green development level. Columns (3) and (4) report the estimated results of local financial effect and financial spillover effect on the gap of green development in model (1), and the coefficients of local financial effect (fin_local) are all significantly negative at the level of $1 \%$, indicating that the improvement of the local financial development level is helpful to narrow the gap of green development. The coefficients of 
TABLE 1: Green total factor productivity.

\begin{tabular}{|c|c|c|c|}
\hline Explained variable & $\begin{array}{l}\text { Input and } \\
\text { output }\end{array}$ & Variable name & Variable definition \\
\hline \multirow{6}{*}{$\begin{array}{l}\text { Green total factor } \\
\text { productivity }\end{array}$} & & Capital input & Physical capital stock of each city \\
\hline & Input & Labor input & $\begin{array}{c}\text { Total number of people employed in the secondary and tertiary } \\
\text { industries }\end{array}$ \\
\hline & \multirow{3}{*}{$\begin{array}{l}\text { Desirable } \\
\text { output }\end{array}$} & Energy resource input & Total amount of electricity and water supply in the whole society \\
\hline & & Economic output & Actual regional GDP \\
\hline & & $\begin{array}{l}\text { Residents' living quality } \\
\text { output }\end{array}$ & Greenery coverage of urban area \\
\hline & $\begin{array}{l}\text { Undesirable } \\
\text { output }\end{array}$ & $\begin{array}{l}\text { Environmental } \\
\text { pollution }\end{array}$ & $\begin{array}{l}\text { Industrial wastewater quantity, industrial sulfur dioxide emissions, } \\
\text { industrial soot emissions, and PM2.5 concentration }\end{array}$ \\
\hline
\end{tabular}

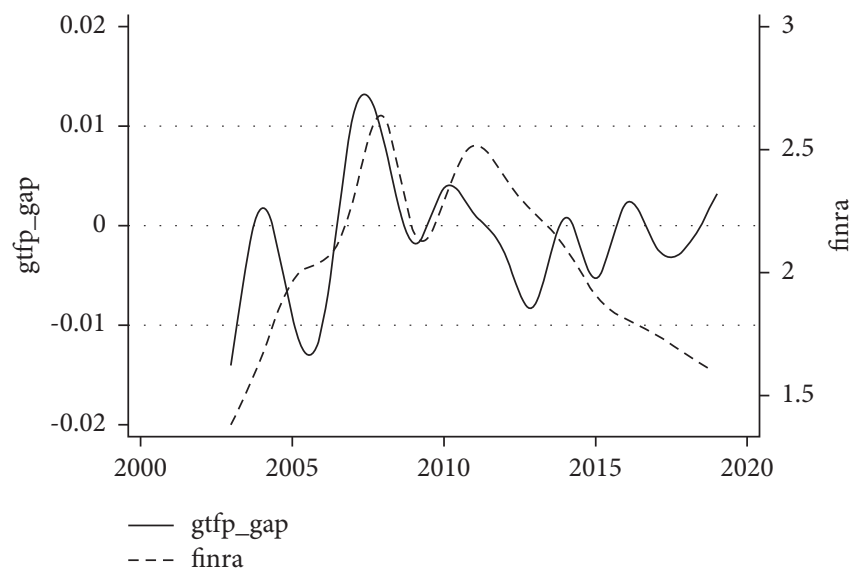

FiguRE 1: Binary curve of the gap between the financial development level and the gap of green development.

TABle 2: Descriptive statistics.

\begin{tabular}{|c|c|c|c|c|c|}
\hline Variables & Obs & Mean & Std dev & Min & Max \\
\hline Gtfp & 4250 & 1.01 & 0.029 & 0.96 & 1.06 \\
\hline Gtfp gap & 4250 & -0.001 & 0.042 & -0.099 & 0.099 \\
\hline Fin_local & 4250 & 0.565 & 0.31 & 0.08 & 6.785 \\
\hline Fin_center & 4250 & 0.01 & 0.009 & 0.001 & 0.102 \\
\hline Lnpgdp & 4250 & 9.849 & 0.75 & 4.358 & 12.786 \\
\hline Lnpopulation & 4250 & 5.687 & 0.899 & 1.552 & 7.923 \\
\hline Fdi & 4250 & 0.002 & 0.003 & 0 & 0.045 \\
\hline Finadp & 4250 & 2.189 & 1.426 & .166 & 14.215 \\
\hline Medical & 4250 & 18.762 & 9.812 & 2.754 & 98.332 \\
\hline
\end{tabular}

TABLE 3: Baseline regression.

\begin{tabular}{lcccc}
\hline Variable & $(1)$ & $(2)$ & $(3)$ & $(4)$ \\
gtfp_gap & Gtfp_gap \\
\hline fin_local & Gtfp & $0.0058^{* *}$ & $-0.0092^{* *}$ & $(-3.11)$ \\
fin_center & $0.0056^{* *}$ & $(2.45)$ & $0.9636^{* * *}$ & $(-3.08)$ \\
Controls & $(2.41)$ & & $(3.71)$ & $(3.33)$ \\
Year/city, FE & & YES & NO & YES \\
$N$ & NO & YES & YES & 4250 \\
R2 & YES & 4250 & $0.8857^{* * *}$ & \\
\hline
\end{tabular}


financial spillover effect (fin_center) are also significant at the level of $1 \%$, but it is positive, indicating that the financial development of central city widens the gap between the central city and other cities in green development. It may be because the increase of the financial development level of the central city can generate a siphon effect, which will attract resources from other cities and thus widen the gap. Therefore, the hypothesis of this paper is initially verified. Hausman test and multicollinearity test are also carried out in this paper before the regression. The results of Hausman test demonstrate that the fixed effect model needs to be selected. The maximum value of VIF test is 1.91, and the average value of 1.40 , far less than 10 , showing that there is no severe problem of multicollinearity.

3.2. Robustness Test and Endogenous Treatment. Even though the related variables have been controlled as much as possible and the two-way fixed effect model has been used, this study may still have possible endogenous problems. To eliminate the problem that the conclusions of this paper might be affected by reverse causality, missing variables, and measurement errors, the following robustness tests are conducted.

3.2.1. Instrumental Variable Method. In model (1), although this paper attempts to control the variables that may affect the financial development level and the gap of green development simultaneously, the error of missing variables may still exist. To alleviate the potential problems of reverse causality, missing variables, and measurement errors, this study employs the instrumental variable method for regression. Based on the research of Feng Tao et al. [9], this study selects the savings balance of urban and rural residents, one period lagging, and the number of employees in the financial sector, one period lagging, as the instrumental variables. The corresponding estimated results are displayed in column (1) of Table 4. In column (1), the estimation result of local financial effect (FIN_local) is significantly negative at the level of $1 \%$, and the estimation result of financial spillover effect (FIN_center) is also significantly negative at the level of $1 \%$. This shows that the significance and sign of explanatory variables have not changed significantly, indicating that the possible existence of endogeneity problem mentioned above does not affect the robustness of the conclusions in this study. In addition, the DWH value and $P$ value of the rationality test for the instrumental variables are 49.3 and 0.00 , indicating that the instrumental variables are effective.

3.2.2. Control the Time Trend Term. Changes in the gap of green development may be influenced by some nonobserved specific factors in the region, which will lead to biased results if they are not considered. Referring to the common practice in the existing literature, this study adds the time trend term of the city to the model and re-estimates the results as shown in column (2) of Table 4. It remains significant after controlling the time trend term, indicating that the nonobserved regional specific factors have no substantial influence on the estimated results in this paper.
3.2.3. Exclude Outliers. The global financial crisis occurred in 2008, and China's financial system was also seriously impacted. Therefore, the samples of 2008 and 2009 are excluded in this paper, and the results are shown in column (3). To prevent the influence of extreme values, this study also adopts the two-sided $1 \%$ winsorization of explanatory variables and explained variables. The results are shown in column (4), which suggests that the conclusions of this paper do not change after considering the outliers.

3.2.4. Change the Measurement Method. Based on the research ideas of Feng Tao, this study changes the year-end loan balance of financial institutions in the city to the yearend deposit balance of financial institutions in the city and re-measures the local financial effect and financial spillover effect. The corresponding estimated results are presented in column (5) of Table 4. The significance of local financial effect and financial spillover effect is basically consistent with the previous result, which shows that the conclusions of this study are robust.

3.3. Mechanism of Action. Financial resources need to be combined with human capital to promote the development of real economy. Human capital is an important factor of production, which can inject growth vitality into urban green development through technological advancement and knowledge progress and use foreign pollution control technologies to provide support for energy conservation and emission reduction. However, due to the different development conditions of different cities, there are significant differences in human capital levels among cities. In this regard, does the role of financial resources in narrowing the gap of green development have substantial differences due to different conditions of human capital? To answer this question, this study introduces the dummy variable of human capital level for verification. According to the existing literature, the ratio of the number of students in general colleges to the total year-end resident population is used to represent the human capital level. Furthermore, when the human capital level is higher than the sample average, it is defined as 1 , and the rest is 0 . Finally, a subsample regression is conducted based on the dummy variable of the human capital level, the results of which are shown in Table 5. The results in column (1) suggest that the local financial effect (fin_local) in cities with a high human capital level is negative but not significant, and financial spillover effect (fin_center) is positive and significant at the level of $10 \%$. The results in column (2) show that the local financial effect in cities with a low human capital level is significantly negative at the level of $5 \%$. The estimated value of financial spillover effect is significantly positive at the level of $1 \%$. In addition, both estimated coefficients are larger and more significant in the absolute value. The above results show that local financial effect and spillover effect can be more significant in cities with relatively low human capital level. The possible reason is that cities with high human capital have more channels to obtain resources for development, and their financial systems are already quite 
TABLE 4: Robustness test and endogenous treatment.

\begin{tabular}{|c|c|c|c|c|c|}
\hline Variables & $\begin{array}{c}(1) \\
\text { Instrumental variable }\end{array}$ & $\begin{array}{l}(2) \\
\text { Control time trend }\end{array}$ & $\begin{array}{c}(3) \\
\text { Exclude abnormal years }\end{array}$ & $\begin{array}{c}(4) \\
\text { Winsorization }\end{array}$ & $\begin{array}{l}\text { (5) } \\
\text { Change the measurement method }\end{array}$ \\
\hline fin_local & $\begin{array}{c}-0.1379^{* *} \\
(-2.90)\end{array}$ & $\begin{array}{c}-0.0089^{* *} \\
(-2.99)\end{array}$ & $\begin{array}{c}-0.0076^{* *} \\
(-2.51)\end{array}$ & & \\
\hline fin_center & $\begin{array}{l}11.5746^{* *} \\
(2.55)\end{array}$ & $\begin{array}{l}0.9815^{* *} \\
(3.70)\end{array}$ & $\begin{array}{c}0.8769^{* *} \\
(3.15)\end{array}$ & & \\
\hline fin_localw & & & & $\begin{array}{c}-0.0182^{* *} \\
(-3.91)\end{array}$ & \\
\hline fin_centerw & & & & $\begin{array}{c}1.2482^{* *} \\
(4.14)\end{array}$ & \\
\hline fin_local1 & & & & & $\begin{array}{c}-0.0026^{* *} \\
(-2.28)\end{array}$ \\
\hline fin_center1 & & & & & $\begin{array}{c}0.8327^{* *} \\
(2.77)\end{array}$ \\
\hline Controls & YES & YES & YES & YES & YES \\
\hline Year/city, FE & YES & YES & YES & YES & YES \\
\hline $\mathrm{N}$ & 4250 & 4250 & 3750 & 4250 & 4250 \\
\hline $\mathrm{R} 2$ & & 0.0797 & 0.0937 & 0.0794 & 0.0768 \\
\hline
\end{tabular}

TABLE 5: Interaction of human capital.

\begin{tabular}{lccc}
\hline Variables & $\begin{array}{c}(1) \\
\text { High-level human capital } \\
\text { gtfp_gap }\end{array}$ & $\begin{array}{c}(2) \\
\text { Low-level human capital } \\
\text { gtfp_gap }\end{array}$ & $\begin{array}{c}\text { (3) } \\
\text { Advancement of human capital } \\
\text { gtfp_gap }\end{array}$ \\
\hline Fin_local & -0.0046 & $-0.0176^{* *}$ & $-0.0364^{* *}$ \\
& $(-1.44)$ & $(-2.52)$ & $2.54)$ \\
Fin_center & $0.4436^{*}$ & $1.6308^{* *}$ & $\left(4.0794^{* *}\right.$ \\
& $(1.78)$ & & $(3.55)$ \\
Fin_local*Edu_H & & & $0.2033^{* *}$ \\
Fin_center*Edu_H & & & $(4.07)$ \\
Edu_H & & & $-7.7228^{* *}$ \\
Controls & & & $(-2.06)$ \\
Year/city, FE & & & 0.0776 \\
N & YES & YES & $(1.28)$ \\
R2 & YES & YES & YES \\
\hline
\end{tabular}

developed, so it is difficult to narrow the gap with the central city only by relying on the progress of the financial level. In cities with low human capital level, their access to resources is relatively limited, and financial resources can play a better role in narrowing the gap when supporting urban development.

The advancement degree of the human capital structure in different regions is a crucial factor that leads to the formation of the regional gap (Zhiyong Liu et al., 2018). To further explore the role of human capital, this study interacts with the local financial effect and financial spillover effect with the advancement level of human capital structure and observes their effects on the gap of green development. Referring to the research of Caselli and Coleman and Zhiyong Liu et al. $[17,18]$, this study classifies human capital as the primary, intermediate, and advanced. The population with junior high school education or below is defined as primary human capital (P1). The population with senior high school and technical secondary school education is defined as intermediate human capital (P2). The population with junior college education or above is defined as advanced human capital (P3). The advancement of human capital structure is calculated as follows:

$$
\mathrm{Edu}_{i t-} H_{\mathrm{it}}=\sum_{k=1}^{3} k * P_{\mathrm{it}},
$$

where $i$ represents the local cities in each province, $t$ represents the corresponding year, and $k$ represents the human capital level. After introducing the advancement of human capital structure into model (1) and (2) is obtained: 


$$
\begin{aligned}
\operatorname{Gtfp} \_g a p_{i t}= & \alpha_{0}+\alpha_{1} \text { Fin_local }_{i t}+\alpha_{2} \text { Fin } \_ \text {center }_{j t}+\alpha_{3} \text { Fin } \_l o c a l_{i t} * \mathrm{Edu}_{-} H_{i t}+\alpha_{4} \operatorname{Fin}_{-} \text {center }_{j t} * \mathrm{Edu}_{-} H_{i t}+\mathrm{Edu}_{-} H_{i t} \\
& +\alpha_{6} \text { Controls }_{i t}+\delta_{i}+\phi_{t}+\varepsilon_{0} .
\end{aligned}
$$

The core of this paper is the coefficients of interaction terms, $\alpha_{3}$ and $\alpha_{4}$. The definitions of other variables are the same as the previous one. The corresponding results are displayed in column (3) of Table 5. The coefficient $\alpha_{3}$ of the interaction term between local financial effect and advancement of human capital structure is 0.2033 , which is significantly positive at the level of $1 \%$, while the coefficient of $\alpha_{1}$ is significantly negative. The coefficient of financial spillover effect itself is positive, but the coefficient $\left(\alpha_{4}\right)$ of the interaction term between financial spillover effect and the advancement of human capital structure is -7.7228 , which is significantly negative at the level of $5 \%$, indicating that the advancement of human capital structure can help to reduce financial siphon effect. In other words, it helps to reduce the role of financial spillover effect in widening the gap of green development. The external financial resources are larger than those of local cities, and the improvement of the human capital level will help to improve the utilization efficiency of external financial resources, thus helping to narrow the gap of green development.

3.4. Mediating Effect. Based on the previous theoretical analysis, financial elements may accelerate the green development of cities by the optimization of industrial structure, the improvement of technological innovation, and the decrease of resource dependence. To test the existence of these three channels of action, this study uses the ratio of the output value of the tertiary industry to that of the secondary industry to represent the optimization of industrial structure (TS) after referring to the practices of Shuai Shao, Chunhui Gan, Jingjing Ceng, etc. [19-21], the urban innovation index to represent the technological innovation level (Innovation), and the proportion of the employees in the extractive industry to the total employed people to represent the resource dependence (RES). Then, model (6) is constructed for investigation:

$$
\begin{aligned}
\operatorname{Medium}_{i t}= & \alpha_{0}+\alpha_{1} \text { Fin_local }_{i t}+\alpha_{2} \text { Fin_center }_{j t} \\
& +\alpha_{3} \text { Controls }_{i t}+\delta_{i}+\phi_{t}+\varepsilon_{0} .
\end{aligned}
$$

TS, innovation, and RES are the three transmission mechanism variables, and the definitions of other variables are the same as before. The results presented in (1-3) of Table 6 show that other estimated coefficients are significant and their signs are in line with expectations except that financial spillover effect is not significant for the optimization of industrial structure. This indicates that the improvement of the local financial development level can promote the optimization of industrial structure, improve technological innovation level, and decrease resource dependence. Therefore, improving the financial development level of the central city can empower the optimization of industrial structure in other cities, but it will lower the innovation level of other cities. Based on the regression results of Table 6 and Table 3 (baseline regression), promoting the optimization of industrial structure, improving the technological innovation level, and decreasing resource dependence all exert the mediating effect of local financial effect in narrowing the gap of green development. Financial spillover effect can also promote the optimization of industrial structure, but deprive local cities of their role in narrowing the gap of green development through improving technological innovation level. The above results demonstrate that financial spillover effect cannot narrow the gap of green development due to other negative factors (such as technological innovation level) although it can improve the optimization of industrial structure.

3.5. Heterogeneity Analysis. Heterogeneity of economic location: China has a vast territory, and different places have huge differences in factors such as the economic development level and resource conditions. From 2003 to 2019, China shifted from the extensive economic development mode with high energy consumption and pollution to the high-quality development mode, so what changes have taken place in the gap of green development in China during this period? Has the high-quality development model achieved results? In this study, the heterogeneity of the gap of green development is further observed by drawing a smooth curve of the gap of green development that evolves over time in different regions. It can be seen from Figure 2 that there is no significant change in the gap of green development in the eastern region, while that in the northeast region increases first and then decreases. Meanwhile, the gap of green development in the central region decreases first and then increases and that in the western region first rises from a negative value to the value above 0 and changes steadily around this value. On the whole, there is no significant change in the gap of green development in the eastern region, while the bandwidth in the western region is the narrowest with relatively consistent trend every year.

Figure 2 illustrates the dynamic evolution figure of the gap of green development in four major economic regions in China, which shows significant differences in the gap of green development in different regions. The empirical results of the location heterogeneity will be shown below. The results in Table 7 suggest that only local financial effect in the central region can narrow the gap of green development. Moreover, local financial effect in the northeast region can widen the gap of green development, and financial spillover effect in the western region can widen the gap of green development. Other results are not significant.

Distance heterogeneity of financial function: according to the research of financial geography, financial spillover effect will change with distance, and its variation trend may not be consistent. Therefore, this study observes the heterogeneity of the financial development level 
TABle 6: Transmission mechanism.

\begin{tabular}{lccc}
\hline Variables & $(1)$ & $(2)$ & $(3)$ \\
& TS & Innovation & $-0.2422^{* *}$ \\
Fin_local & $0.1434^{* *}$ & $2.2249^{* *}$ & $(-2.40)$ \\
& $(2.63)$ & $(2.02)$ & 9.3663 \\
Fin_center & $4.1586^{* *}$ & $-727.0164^{* *}$ & $(1.61)$ \\
Controls & $(2.08)$ & $(-6.56)$ & YES \\
Year/city, FE & YES & YES & YES \\
$N$ & YES & YES & 4250 \\
R2 & 4250 & 4000 & 0.9373 \\
\hline
\end{tabular}
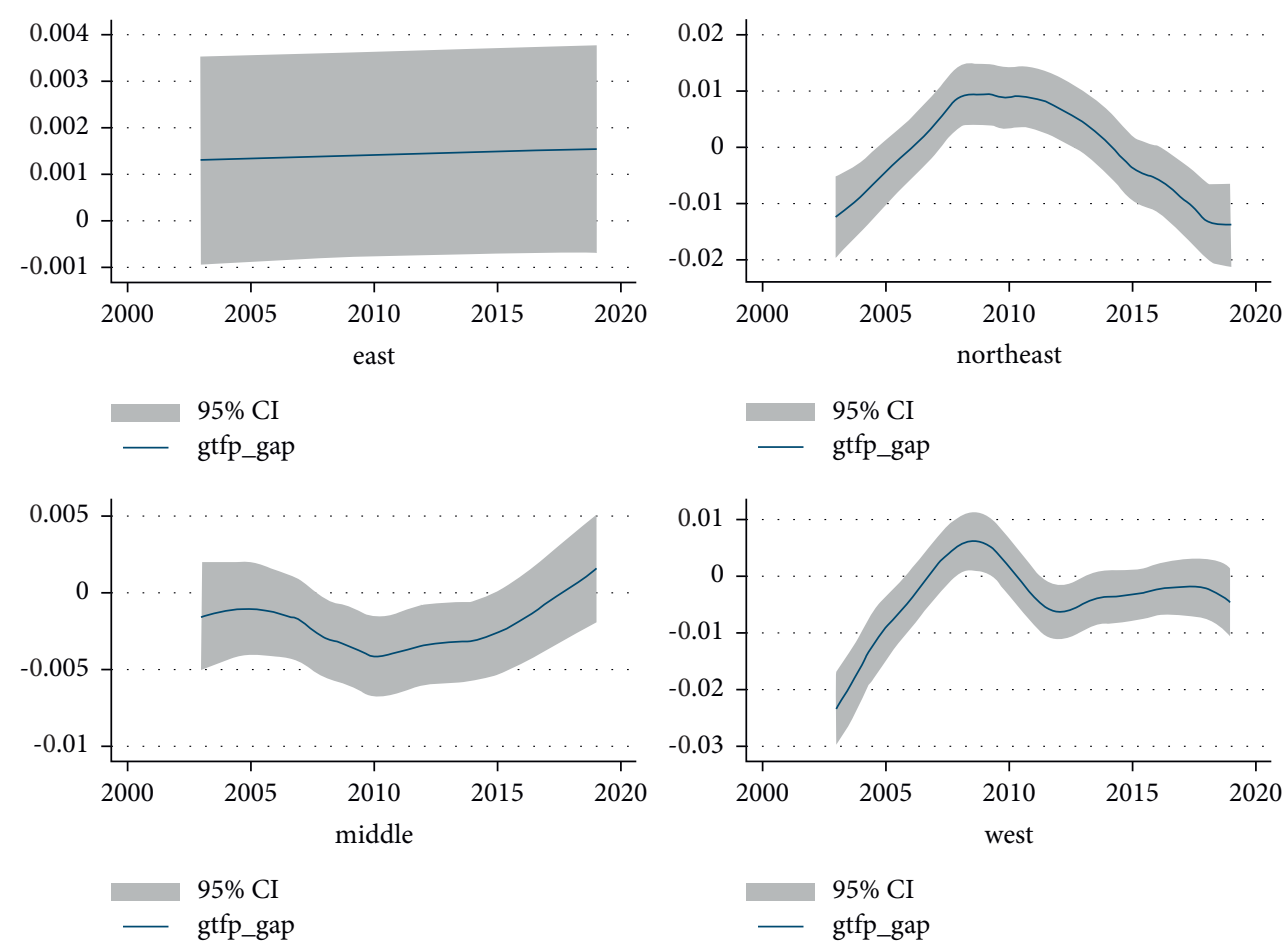

FIgURE 2: Dynamic evolution figure of the gap of regional green development.

TABLE 7: Location heterogeneity.

\begin{tabular}{|c|c|c|c|c|}
\hline Variables & $\begin{array}{c}(1) \\
\text { Eastern region } \\
\text { Gtfp_gap }\end{array}$ & $\begin{array}{l}\text { (2) } \\
\text { Northeast region } \\
\text { Gtfp_gap }\end{array}$ & $\begin{array}{l}\text { (3) } \\
\text { Central region } \\
\text { Gtfp_gap }\end{array}$ & $\begin{array}{c}(4) \\
\text { Western region } \\
\text { gtfp_gap }\end{array}$ \\
\hline Fin_local & $\begin{array}{c}-0.0011 \\
(-0.12)\end{array}$ & $\begin{array}{c}0.0137^{*} \\
(1.69)\end{array}$ & $\begin{array}{c}-0.0080^{* *} \\
(-2.14)\end{array}$ & $\begin{array}{c}--0.0107 \\
(-1.23)\end{array}$ \\
\hline Fin_center & $\begin{array}{c}0.8632 \\
(1.56)\end{array}$ & $\begin{array}{c}0.6838 \\
(1.05)\end{array}$ & $\begin{array}{c}0.4969 \\
(1.07)\end{array}$ & $\begin{array}{r}1.3336^{*} \\
(1.92)\end{array}$ \\
\hline Controls & YES & YES & YES & YES \\
\hline Year/city, FE & YES & YES & YES & YES \\
\hline$N$ & 1411 & 510 & 1598 & 731 \\
\hline $\mathrm{R} 2$ & 0.1498 & 0.2468 & 0.1379 & 0.2602 \\
\hline
\end{tabular}

by setting groups based on distance, and the corresponding results are presented in Table 8 . The results in columns (1) and (4) show that neither local financial effect nor financial spillover effect in cities in the nearest group and the farthest group is significant. The results in columns (2) and (3) show that the improvement of the financial development level can dramatically reduce the gap of green development in the group in which cities have a distance of 100-200 KM from the central city, and financial spillover effect can significantly expand the gap of green development when cities have a distance of 100-300 KM from the central city. 
TABLE 8: Distance heterogeneity.

\begin{tabular}{lcccc}
\hline & $(1)$ & $(2)$ & $(3)$ & $(4)$ \\
Variables & $100 \mathrm{KM}$ & $100 \sim 200 \mathrm{KM}$ & $200 \sim 300 \mathrm{KM}$ & Over $400 \mathrm{KM}$ \\
\hline Fin_local & -0.0153 & $-0.0095^{* *}$ & -0.0116 & $(-1.32)$ \\
& $(-1.14)$ & $(-2.01)$ & $3.0814^{* *}$ & $(-1.31)$ \\
Fin_center & 0.4483 & $1.4891^{* *}$ & $(2.88)$ & 1.7953 \\
Controls & $(1.55)$ & $(2.34)$ & YES & $(0.97)$ \\
Year/city, FE & YES & YES & YES & YES \\
$N$ & YES & YES & 1105 & YES \\
R2 & 901 & 1547 & 0.0368 & $c$ \\
\hline
\end{tabular}

According to the results in Table 8, local financial effect can only play a role in narrowing the gap of green development when the city is 100-200 KM away from the central city. The magnitude and significance of financial spillover effect show an inverted " $U$ " trend of first increasing and then decreasing with the distance. The nearby pollution transfer effect in environmental regulations reaches its peak at $150 \mathrm{KM}$, so it is possible that the pollution of nearby cities around this distance is more serious and the green development is at a relatively weak level, which can also verify the conclusion that local financial effect narrows the gap of cities that are 100-200 KM away from the central city [22].

\section{Conclusions and Policy Recommendations}

Regarding the function of financial resources on the highquality green development, special attention should be paid to the matching of regional coordination and balance with the needs of the real economy. Based on the data of Chinese cities, this study divides the financial function into local financial effect and spillover financial effect of the central city, empirically investigates the influence of China's financial geography structure on the gap of green development and its mechanism, and discusses its heterogeneity, which provides empirical evidence for studying the influence of financial geography structure on the gap of green development. The main conclusions are as follows. First, local financial effect helps to narrow the gap of green development between local cities and the central city, and financial spillover effect has an effect of widening the gap. The advancement of local human capital structure helps to relieve the negative financial spillover effect and narrow the gap of green development. Second, in both local financial effect and financial spillover effect, the optimization of the industrial structure has exerted the mediating effect of narrowing the gap of green development. Local financial effect narrows the gap of green development by promoting innovation, while financial spillover widens the gap of green development by restraining innovation. Local financial effect can reduce the dependence of urban resources and then narrow the gap of green development. The financial development of the central city has no significant effect on the resource dependence of local cities. Third, in cities that are 100-200 KM away from the central city in the central region of China, the local financial effect can significantly narrow the gap of green development, while it significantly widens the gap in the northeast region. In the meantime, the local financial effect in other regions is not significant. Financial spillover effect presents an inverted " $U$ " trend with the variation of distance. The policy recommendations of this paper are as follows. First, local financial resources possess the advantages of cost in facilitating the development of real economy. It is of vital significance to concentrate financial resources on the tertiary industry and actively innovative enterprises, alleviate the development obstacles triggered by resource dependence, and coordinate the supply of local financial resources to narrow the gap of regional green development. Secondly, promoting the advancement of the human capital structure is an important channel to reduce the financial siphon effect of the central city. Local governments should strengthen the talent introduction, improve the supporting system of talent introduction, attract high-level and high-quality talents to settle down, improve the efficiency of resource utilization, and narrow the gap. Finally, there are significant differences between urban positioning and green development in different places. When formulating development strategies, we should make overall plans in accordance with local conditions, comprehensively consider the matching between policies and reality, implement scientific and perfect toplevel design, and accelerate green and high-quality development.

\section{Data Availability}

The data used to support the findings of this study are available from the corresponding author upon request.

\section{Conflicts of Interest}

The authors declare that they have no conflicts of interest.

\section{Acknowledgments}

This research was financially supported by the National Social Science Fund of China (Grant no. 18BJY249).

\section{References}

[1] M. P Conzen, "A transport interpretation of the growth of urban regions: an American example," Journal of Historical Geography, vol. 1, no. 4, pp. 361-382, 1975.

[2] H. C Reed, The Pre-eminence of International Finance Centers, Praeger, Santa Barbara, California, 1981. 
[3] A. E. Tschoegl, "International banking centers, geography, and foreign banks," Financial Markets, Institutions \& Instruments, vol. 9, no. 1, pp. 1-32, 2000.

[4] Y. S. Park, "The economics of offshore financial centers," The Columbia Journal of World Business, vol. 17, no. 4, pp. 32-33, 1982.

[5] J. Huang, "Analysis of internal motivation of financial cluster," Journal of Industrial Technological Economics, vol. 30, no. 3, pp. 129-136, 2011.

[6] X. Che, H. Bu, X. Liang, S. Wang, and S. Wang, "A theoretical model of financial cluster motivation," Journal of Management Sciences in China, vol. 15, no. 3, pp. 16-29, 2012.

[7] J. Sun and H. Li, "Financial cluster and upgrading of industrial structure-Empirical analysis from provincial economic data in 2003-2007,” Economist, vol. 11, no. 3, pp. 80-86, 2012.

[8] Li Lin, Yi Ding, and Z. Liu, "Spatial econometric analysis of spillover effects of financial cluster on regional economic growth," Journal of Financial Research, vol. 23, no. 5, pp. 113-123, 2011.

[9] F. Tao, J. Hu, S. Li, and J. Wei, "How does financial geographical structure affect enterprise productivity? On the structural reform of financial supply," Economic Research Journal, vol. 52, no. 9, pp. 55-71, 2017.

[10] M. A. Petersen and R. G. Rajan, "Does distance still matter? The information revolution in small business lending," The Journal of Finance, vol. 57, no. 6, pp. 2533-2570, 2002.

[11] S. Agarwal and R. Hauswald, "Distance and private information in lending," Review of Financial Studies, vol. 23, no. 7, pp. 2757-2788, 2010.

[12] B. Klagge and R. Martin, "Decentralized versus centralized financial systems: is there a case for local capital markets?" Journal of Economic Geography, vol. 5, no. 4, pp. 387-421, 2005.

[13] G. Sun and Y. Fan, "The essence, function and path choice of financial center," Management World, vol. 8, no. 11, pp. 1-13, 2013.

[14] W. Li, "Governance reform of financial institutions: top-level design needed," Nankai Business Review, vol. 15, no. 3, p. 1, 2012.

[15] J. T. Pastor and C. A. K. Lovell, "A global Malmquist productivity index," Economics Letters, vol. 88, no. 2, pp. 266-271, 2005.

[16] X. Cao and L. Zhang, "Direct impact of financial support on technological innovation and spatial spillover effect-Based on China's provincial spatial panel, Tobit model, from 2003 to 2013," Management Review, vol. 29, no. 7, pp. 36-45, 2017.

[17] Z. Liu, H. Li, Y. Hu, and C. Li, "The advancement of human capital structure and economic growth-On the formation and narrowing of the gap between the eastern, central and western regions," Economic Research Journal, vol. 53, no. 3, pp. 50-63, 2018.

[18] F. Caselli and W. J. Coleman II, "The U.S. Structural transformation and regional convergence: a reinterpretation," Journal of Political Economy, vol. 109, no. 3, pp. 584-616, 2001.

[19] S. Shao and L. Yang, "Abundance of natural resources, dependence of resource industries and regional economic growth in China," Management World, vol. 14, no. 9, pp. 26-44, 2010.

[20] C. Gan, R. Zheng, and F. Yu, “The influence of China's industrial structure change on economic growth and fluctuation," Economic Research Journal, vol. 46, no. 5, pp. 4-16, 2011.
[21] J. Ceng and D. Zhou, "The influence of government innovation investment and city scale level on urban innovation ability," Urban Problems, vol. 5, no. 5, pp. 55-64, 2019.

[22] K. Shen, G. Jin, and X. Fang, "Has environmental regulation caused pollution to transfer nearby?" Economic Research Journal, vol. 52, no. 5, pp. 44-59, 2017. 